\title{
Phraseology and the Implementation of Cognitive Grammar in Translation Didactics
}

\section{La fraseología y la implementación de la gramática cognitiva en la didáctica de la traducción}

\author{
Olaf Immanuel SEEL \\ Ionian University of Corfu \\ seel@ionio.gr
}

\begin{abstract}
This paper aims to instrumentalize cognitive grammar for translation didactics and to demonstrate its importance for translation trainees as a tool for fostering their cultural competence in and between their working cultures and, thus, for improving their overall translation competence. Methodologically, this will be realized as evidenced by the implementation of cognitive grammar on one particular Greek phraseological unit. In this context, the overarching theoretical point of reference for any translational purvey is functional translation theory. It will be shown that cognitive grammar constitutes a useful conceptual tool to assist and foster translation didactics in dealing with culture-specific elements of the translation trainees' working languages.
\end{abstract}

Keywords: tool for translation didactics; translation competence; cultural specificities; phraseologisms; cognitive grammar.

Resumen: El objetivo de este artículo es aplicar la gramática cognitiva en la didáctica de la traducción y demostrar su importancia para los estudiantes de traducción como una herramienta para fomentar su competencia cultural en y entre sus culturas de

Olaf Immanuel SEEL Phraseology and the Implementation of Cognitive Grammar in Translation Didactics 
trabajo y, por tanto, para mejorar su competencia traductora general. En términos metodológicos, esto se realizará mediante la aplicación de la gramática cognitiva en una unidad fraseológica griega concreta. En este contexto, el punto de referencia teórico general para cualquier propósito de traducción es la teoría de la traducción funcional. Se demostrará que la gramática cognitiva constituye una herramienta conceptual útil para ayudar y fomentar la didáctica de la traducción en el tratamiento de los elementos específicos de la cultura de las lenguas de trabajo de los estudiantes de traducción.

Palabras clave: herramienta para la didáctica de la traducción; competencia traductora; especificidades culturales; fraseologismos; gramática cognitiva.

\section{INTRODUCTION}

The issue of phraseology and translation is not neglected in translation studies. In the past decades, much research has focused on the problem(s) raised by the translation of phraseological units (henceforth PUs) from different angles of intellectual purview. $^{1}$

As early as 1969, Nida and Taber refer to the translation of PUs as being an issue that demands utmost sensitivity. A few years later, Gläser (1984) offers an equivalencefocused study on the translation of PUs with regard to the language pair English German. Also seminal is Baker's (1992) analysis of possible strategies of the translation of PUs. Corpas (1996, quoted in: Arroyo 2009, 54) and Roberts (1998, quoted in: Arroyo 2009, 54) explain unsatisfactory results in translation with the unfortunate translation of PUs offered in multilingual and bilingual dictionaries. Also interesting are Sabban's (1999) and Mogorrón Huerta's and Albaladejo-Martínez' (2018) edited volumes which include a series of chapters viewing PUs and translation from a variety of interdisciplinary angles. At the same time, the rather long-time span between these two volumes delineates the still vibrant interest in PUs and translation. A more direct reference to the translation of PUs and translation didactics can be found in Corpas (2001, quoted in: Arroyo 2009, 54) who emphasises the importance of a very good command of the translator's working languages for the successful translation of PUs and the need for a stronger emphasis on the translator's training to focus on language training because "[i]n some cases, translators utterly fail to identify these units, a kind of behaviour that seems to point at the translator's poor command of the language in

1. Due to the rather sizeable relevant literature that can be found on this research object, simply listing it seems unwarranted in this instance; whereas it could perhaps be more useful in a wider ranging study on PUs and translation. Instead, I believe it is pertinent to reference representative previous researches that are paradigmatic and will, in short, illustrate the heterogeneity of specific topics and approaches that have heretofore been in PUs and translation research.

Olaf Immanuel SEEL Phraseology and the Implementation of Cognitive Grammar in Translation Didactics
CLINA

vol. 6-2, December 2020, 15-32

eISSN: 2444-1961

Ediciones Universidad de Salamanca - CC BY-NC-ND 
question». Close to Baker's translation strategies for PUs is Kuzmins (2007, quoted in: Subbotina 2013, 1490) proposition of possible translation solutions for PUs. An interlingual, contrastive approach to translating PUs is presented in the edited volume of Kittel et al. (2004) and, more recently, in Hallsteinsdóttir and Farø (2010). Finally, an indirect link to translation didactics is also drawn by Hallsteinsdóttir (2011) who from a linguistic point of view analyses the phraseological competence of the translator.

Common to all the research carried out on this area is the central problem that arises from the translation of PUs, i.e., the divergence between its (gradually) frozen polylexical structural and semantic nature and its, frequently, metaphorical meaning which results in their lack of semantic transparency or, in other words, in their opacity. As will be shown later on (cf. 2.1.), the opacity of PUs is deeply culture-bound. However, in the sizeable research on PUs and translation, the salience of the cultural aspect for the translation of PUs is not paid in-depth attention to. ${ }^{2}$ And, notwithstanding, the variety of approaches and the more or less indirect emphasis on the cultural factor in translation studies research on PUs, if at all, I endorse the view of Sulkowska (2013) that phraseodidactics have to also be implemented in translation didactics, i.e., that translation didactics needs to offer concrete and theoretically grounded help to translation trainees in order to deal with PUs efficiently. However, there seems to not be much awareness of the importance for translation didactics to deliver such methods and tools to unveil the opacity of PUs for the sake of its correct translation, let alone with an emphasis on the cultural aspect of PUs. As far as I know, no such tools or methods have yet been offered by research. Thus, it remains unclear how, under which theoretical premises and to what extent translation didactics can indeed satisfy such a demand with a special focus on the cultural aspect of PUs. ${ }^{3}$

This raises several questions: Is there a methodological and practical tool based on theoretically grounded premises that will help translation trainees on how, if learned, to handle it, i.e., to open up the culture-specific opacity of PUs in a translationally functional manner? And would that be a tool which would be applicable anytime in class, as well as later on, if needed, in the profession? The answer is clear, and I would argue that it is, Yes.

This paper would like to contribute to the discourse surrounding the subject. The aim of this study is to introduce a new methodological tool whose main purpose is to

2. Except for Arroyo $(2009,52)$ where the affinity of cognitive grammar with the analysis of the cultural dimension of PUs is mentioned, to some extent, the issue of the culture-boundedness of PUs is merely referred to more generally as a "problem». However, no specific methodological solution for engaging with the cultural aspect of PUs in translation didactics is proposed.

3. A culturally marked tool, which serves translation didactics with regard to the in-class-analysis of the source-text and the production of a functionally correct target-text is the concept of «contrastive text prototypologies», conceived and presented from an intralingual point of view in Seel (2015) and with regard to interlingual translation in Seel (2015a). This tool is based on Christiane Nord's $(1998,351)$ concept of «translational top-down-procedures».

Olaf Immanuel SEEL Phraseology and the Implementation of Cognitive Grammar in Translation Didactics
CLINA

vol. 6-2, December 2020, 15-32 elSSN: 2444-1961

Ediciones Universidad de Salamanca - CC BY-NC-ND 
assist translation didactics in unveiling the opacity and the culture-boundedness of PUs. In these terms, the overarching goal in mind is to offer a tool that can foster the cultural competence of translation trainees in and between their working cultures which will help them to improve their overall translation competence ${ }^{4}$. Methodologically, this will be shown through the implementation of cognitive grammar (henceforth CG) using one PU from Greek as working language. The findings will be evaluated in relation to functional translation theory. (Cf. Reiß and Vermeer ${ }^{2} 1991$; Nord 1993)

This is a multidisciplinary task that involves a theoretical first part, as well as a second more practical one. Methodologically, the theoretical part, on which the subsequent second main part of the study will be based, involves combining phraseology, CG, and translation studies. The practical part will realize the instrumentalization of CG utilizing a PU from the working language mentioned above.

\section{THEORETICAL BACKGROUND}

\subsection{Phraseological units and translational challenge}

What makes PUs a translational challenge? In order to specify this, let us have a quick glance at the main characteristics of PUs. According to Burger $\left({ }^{4} 2010,108\right)$ and Hallsteinsdóttir (2011), notwithstanding the sheer variety of PUs (cf. Burger ${ }^{4} 2010$, 33-58), all categories of PUs have the following inherent characteristics in common: polylexicality, (gradual) frozenness, and (gradual) idiomaticity. While the first two characteristics do not pose any translation problem, the latter one decisively poses the translational issue of opacity. To facilitate and accelerate comprehension, I would like to cite a well-known definition of the term «phraseological» (Burger, Buhofer and Siam 1982, 1; my translation):

Phraseological is a combination of words whose 1. syntactic and semantic regularities of their specific combination do not constitute a fully explainable unit of meaning and if

2. the combination of words is, like a lexeme, common in a linguistic community.

Thus, on the grounds of this definition, we can distinguish between PUs in the wider and in the narrower sense. In the case that only the second of the aforementioned conditions applies, we have a PU in the wider sense. Such PUs are more or less

4. Due to space constraints, I shall not present a separate section on the cultural dimension of translation competence. Instead, mentioned for the sake of conceptual orientation, I rely on Witte (2000) and the functionally-oriented two central axes of translation competence, i.e., "competence-in-cultures» (German: Kompetenz-in-Kulturen) and the "competence-between-cultures» (German: Kompetenz-zwischen-Kulturen). For further reading see also Witte (1987).

Olaf Immanuel SEEL Phraseology and the Implementation of Cognitive Grammar in Translation Didactics
CLINA

vol. 6-2, December 2020, 15-32 elSSN: 2444-1961

Ediciones Universidad de Salamanca - CC BY-NC-ND 
fixed word combinations whose meaning is easily derived from their structure and components. Burger $\left({ }^{4} 2010,36\right)$ subsumes under this category structural PUs, i.e., PUs that only function to establish a grammatical relation, e.g., "with regard to", "not only ... but also", as well as communicative PUs whose function is to assist in realizing communication acts, e.g., "Good morning!», «in my opinion». These two categories comply with the aforementioned main criteria of polylexicality and (gradual) frozenness. In the other case, however, in which both conditions (1) and (2) apply, the third characteristic of idiomaticity is added. According to Burger (42010, 36-37), PUs that comply with all three characteristics, i.e., with (1) and (2) as cited above, are referential PUs. Referential PUs refer to objects, processes or situations of the real (or fictive) world, and he classifies them as nominative referential PUs (objects), e.g., in German Das schwarze Brett, and propositional referential PUs (processes or situations), e.g., in German Morgenstund hat Gold im Mund. In these terms, the more idiomatic referential PUs are, the less explainable their imagery is from their syntactic and semantic regularities and thus, the more intense it is (cf. Burger $\left.{ }^{4} 2010,96\right)$. This constitutes their figurativeness which generates their opacity and, at the same time, highlights the translational challenge they pose.

However, and if this alone would not be enough of a translational challenge, referential PUs, especially propositional ones with intense imagery, are often deeply entrenched in their source-culture, not only reflecting historical data but also a culturespecific mindset that according to Scherner (1984, 62; my translation) includes «the whole gamut of norms, conventions, action planning [...] all the values, emotions, connotations by which native speakers and hearers are influenced when producing or receiving a text.» In the words of Hallsteindóttir (1997, 561; my translation):

Phraseologisms are universal linguistic phenomena whose construal and use is historically and culturally determined. Due to differences in the non/-linguistic reality, due to different conditions of life, customs and habits, and mentality, a different need for phraseological designation arises which can be motivated by different linguistic images, metaphors and meaning relations. In these terms, phraseologisms are bearers of cultural specificities.

This becomes especially evident with the so-called "comparative referential PUs», e.g., in German frieren wie ein Schneider or dumm wie Bohnenstroh, but is more or less inherent in all referential PUs (cf. Burger $\left.{ }^{4} 2010,46\right)$.

Summing it up: Semantic opacity of PUs, which is the main reason they pose a challenge to translation, comes down to two reasons: 1 . The impossibility of construing meaning on the grounds of their syntactic and semantic regularities, and 2. their gradual culture-boundedness, which can be referentially more overt, as it is in comparative referential PUs, or more covert, as it is in simple referential PUs. In any case, the cultureboundedness of PUs goes along with one of the main axioms of functional translation theory which clearly stipulates that the deepest structural level of language is the cultural one (cf. Vermeer 1986).

Olaf Immanuel SEEL

Phraseology and the Implementation of Cognitive Grammar in Translation Didactics
CLINA

vol. 6-2, December 2020, 15-32

elSSN: 2444-1961

Ediciones Universidad de Salamanca - CC BY-NC-ND 
In view of the above, it can be concluded that it should be possible to make PUs transparent if their figurative content, as well as their inner culture-boundedness is revealed. With regard to translation, this undoubtfully touches upon the translator's cultural competence. Hence, it is all too obvious that this issue is of major concern for translation didactics whose task is, among others, to offer methods and means for cultivating and fostering the culture competence in and between the working languages of translation trainees (cf. Witte 2000; Seel 2015).

Before presenting an instrumentalization of CG in translation didactics, I would like to outline the main axes of CG.

\subsection{Central Axes of Cognitive Grammar}

CG, developed by the American linguist Ronald W. Langacker in the 1980s, is grounded on the following main theoretical premises (Langacker 1987; 1991; 1997) wherein:

a) Knowledge processing is realized by categorization and schematization which leads to the assumption that there are no rules for language learning, learning production and the understanding of language. Instead, there are links of categorization that connect schemes with each other. More specific schemes are called 'instances'.

b) In the symbolic nature of language all linguistic structures constitute pairs of form and meaning, and form is not attributed autonomy. Thus, the syntax and the morphology of language units do have semantic relevance. This has as an affect that language knowledge and knowledge about the world cannot be disassociated from each other, which, subsequently makes a separation of semantics and pragmatics obviate.

c) Grammar is conceptualisation. Grammatical phenomena are considered as concepts that are dependent on the same conditions as semantic phenomena, e.g., processes of categorization, profiling, motivational patterns.

d) Language knowledge is usage-based: Linguistic meaning and grammatical structures are generated and change by language use and result from entrenchments and cognitive routines. (Cf. Ziem n.d.)

e) All language structure can be described in cognitive terms.

f) Semantics are viewed from an encyclopaedic perspective, according to which «a lexical meaning resides in a particular way of accessing an open-ended body of knowledge pertaining to a certain type of entity [...] hav[ing] varying degrees of centrality» (Langacker 1997, 39).

In view of the above, CG explores and explains language and language use from a semantic point of view. Meaning in language is thereby entangled with the mental experience of the language users. Thus, when describing language and language use on the grounds of the mental experience of the conceptualizer, one can deduce that the meaning of language is not only made up by the specific communication situation but

Olaf Immanuel SEEL Phraseology and the Implementation of Cognitive Grammar in Translation Didactics
CLINA

vol. 6-2, December 2020, 15-32 elSSN: 2444-1961

Ediciones Universidad de Salamanca - CC BY-NC-ND 
also by factors pertinent to the one who conceptualises. According to $C G$, the meaning of a linguistic unit consists of two aspects: the conceptual content (cf. e.g., Langacker 1997, 43-54) and its imagery (Langacker 1997, 55-74). The first aspect refers to specific cognitive domains that are activated when using a specific linguistic expression. Langacker refers to it as "cognitive domains", in which meaning is entrenched. This includes «basic domains» which are the domains of time and space. And, then, there are «non-basic domains", i.e., "[a]ny kind of conceptualization [...] capable of being exploited for semantic purposes» (Langacker 1997, 45). Non-basic domains are, for example, sensory modalities, i.e., visual, acoustic, olfactory perception, taste and smell, but also the domains of emotion and those of synesthetic domains, such as complex knowledge systems. Hence, domains may have several dimensions that also reside in their common similarity or their difference. Due to the fact that not all dimensions can be naturally integrated in one specific space, Langacker $(1987,47,150)$ proposes the term «matrix» which comprises all the domain dimensions an expression evokes, that are not closely connected to each other. Thus, in pluridimensional compact space we deal with 'positions', while in a matrix with 'configurations '. (Cf. Wildgen 2014, 4-5)

The second aspect of the meaning of a linguistic unit refers to the human ability of moulding and expressing the content of a specific domain in different ways. Besides the term «imagery» to designate this ability of the conceptualizer, Langacker (1997, chapter 3) also uses the term "scene construal», where he defines "scene» as the (partial) conceptualization by the language user of content in a specific real or fictive moment of time in a given place either of the mental world we construct or real world.

Hence, "conceptualization» is the umbrella term for all the mental processes that are connected with the cognitive capacities of a human being and that contribute to the making of the mental representations of the reality experienced by the individual. This suggests that the totality of the individual experience of the conceptualizer, as well as his/her conceptual experiences, shape meaning at least to the same extent as the objective reality itself and determines the use of specific linguistic means. Thus, linguistic utterances cannot be considered as only a direct representation of the nonlinguistic world, they also reflect the mental world of the conceptualizer who sees the non-linguistic reality from a specific point of view, namely, his own one. (Cf. Gawel 2014, 132-133). Both reveal the cultural affinity of CG. In Langacker's (1997, 240-241; emph. ibid) own words:

I would claim [...] that despite its mental focus, cognitive linguistics can also be described as social, cultural, and contextual linguistics. One manifestation of its cultural basis is the doctrine of encyclopedic semantics. An expression is meaningful by virtue of evoking a set of cognitive domains and imposing a certain construal on their content. Any kind of conceptualization can function as a domain, and any facet of our open-ended knowledge of an entity can in principle be evoked as part of how an expression designating it is understood on a given occasion. In large measure these domains consist of cultural knowledge: most of what we say pertains to cultural constructions or to entities whose apprehension is in some way culturally influenced. Moreover, language

Olaf Immanuel SEEL

Phraseology and the Implementation of Cognitive Grammar in Translation Didactics
CLINA

vol. 6-2, December 2020, 15-32

elSSN: 2444-1961

Ediciones Universidad de Salamanca - CC BY-NC-ND 
itself is recognized as the creation and reflection of a culture as well as a primary instrument for its constitution and transmission.

All the above suggest that CG mental focus does, besides the individual mental performance, take well into account various aspects of language, specifically, situation, context and culture-specific mindset, that are determined by culture and, at the same time, reflect culture.

Thus far, I have sketched out the main axes of CG. In the following section, I will apply CG on translation didactics using a Greek propositional referential PU. This will be realized by using specific classes of conceptualization and scene construal of CG that are particularly relevant for the analysis of PUs in translation didactics. As with all classes of CG construal, they comply with conceptions in every domain.

\section{INSTRUMENTALIZING COGNITIVE GRAMMAR FOR TRANSLATION DIDACTICS: THE CASE OF PHRASEOLOGISMS}

\subsection{Salient classes of CG conceptualization and construal for PUs and translation didactics}

"An expression's meaning is not just the conceptual content it evokes. Equally important is how that content is construed.» (Langacker 1997, 55)

According to CG a linguistic expression is made up of two basic components, i.e., the conceptual content and its particular manner of construal (Langacker 1997, 43). For the instrumentalization of $C G$ in translation didactics with regard to the translation analysis of PUs, not all of the above-mentioned classes of conceptualization and construal seem relevant. It is obvious that a specific selection of conceptual and construal classes has to be implemented.

The first and basic criterion of such a selection is the very specific nature of the object of analysis itself, i.e., the one of PUs. I shall call it the 'functional' criterion of implementation of CG in translation didactics. As has been shown above (cf. 2.1.), the main translational obstacle of PUs is their opacity which, in short, is due to the figurative or metaphorical semantic value. Hence, it is only specific conceptual and construal classes of CG that will have to be implemented in order to assist translation trainees in revealing and understanding the figurative, as well as cultural nature of a specific PU. The classes of $C G$ that will be used to unveil the figurative content of the PU will be called 'functional class 1'. Additionally, a further class of CG will be implemented for the unveiling of the culture-boundedness of a specific PU. This class is designated as 'functional class 2' of the implementation of PUs in translation didactics.

Olaf Immanuel SEEL Phraseology and the Implementation of Cognitive Grammar in Translation Didactics 
The second criterion of selection is a pedagogical one. If a tool is to be effectively integrated in didactics in general and in translation didactics in particular, it has to also be easily applicable. The applicability and efficiency of a tool is predominantly determined by its easy practicality. This is all the more the case, given time restraints in translation didactics class.

Thus, given both the functional and pedagogical criteria, I shall focus on the following classes of $C G$ in its instrumentalization for the translational analysis: It is necessary to analyze the conceptual content of the Greek PU. This will be done on the grounds of the 'domains' it evokes, which I shall call 'functional class 1', "domain being defined as any kind of conception or mental experience» (Langacker 1997, 50). In this context, it will be shown that domains in PUs are genuinely tripartite, consisting of a series of connections between a source space, a target space and a blended space, as it is also the case with genuine metaphors (cf. Ibid., 51). By means of this first step, the figurative nature and its mental conception will be unveiled.

In a next step, the specific construal of the PU will be envisaged. CG construal - or imagery - comprises four dominant pillars, i.e., 1. specificity, 2. focusing, 3. prominence, and 4. perspective. The three latter are subdivided as follows: focusing (foreground vs. background, composition, and scope), prominence (profiling and trajectory/landmark alignment) and perspective (viewing arrangement and the temporal dimension). The term specificity refers to "the level of precision and detail at which a situation is characterized» (ibid.) or, conversely, its "different levels of abstraction or schematicity» (Langacker 2008, 243). «Foreground» and «background» refers to our «ability to conceive of one situation against the background of another» (ibid.), "composition» stands for the symbolic complexity in the meaning of an individual expression, the «hierarchical arrangement [...] of composite symbolic structures» (Langacker 1997, 60), and "scope» is "defined as the extent of the content an expression evokes in active domains on a given occasion of its use» (Langacker 2008, 243). With regard to the third class of scene construal, specifically, prominence, "profiling" refers to the "reference within a conceptualization" (ibid.) and «trajectory/landmark alignment» to "the relative salience of participants in a profiled relationship» (ibid.). Finally, the term «perspective» encompasses «a variety of factors pertaining to how a scene is 'viewed'» (ibid.).

In the following analysis (cf. 3.2), I shall concentrate on the functionally important scene construal class of focusing, i.e., 'functional class 2', because it will essentially contribute to revealing the culture-boundedness of the $\mathrm{PU}$, thus strengthening the cultural competence of translation trainees. ${ }^{5}$ The emphasis will thereby lie on

5. The implementation of the construal class of focusing will be confined to the aspects of backgrounding and foregrounding which explains the arrangement of conceptual content/knowledge and, thereby, unveils the culture-boundedness of linguistic manifestations. The other two components of focusing, i.e., composition and scope, will not be included in the implementation because they do not essentially contribute to the scope of the investigation. This goes for all the other construal classes of CG too.

Olaf Immanuel SEEL Phraseology and the Implementation of Cognitive Grammar in Translation Didactics
CLINA

vol. 6-2, December 2020, 15-32

elSSN: 2444-1961

Ediciones Universidad de Salamanca - CC BY-NC-ND 
the specific aspects of 'foregrounding against backgrounding'. When putting foregrounding against backgrounding in a linguistic expression, "[t]he categorizing structure lies in the background, taken for granted as a preestablished basis for assessment, while the target is in the foreground of awareness as the structure being observed and assessed» (Langacker 1997, 58). This juxtaposition will point to and reveal the culture-specific elements of the PU that are contextually presupposed and can be subsumed under the term «mindset» (Scherner 1984, 62) of the speaker, without the knowledge of which the culture-bounded opacity of a PU cannot be unveiled. As part of other discourse elements (e.g., context, prior discourse, salience of discourse patterns, etc.) which make up the "current discourse space (CDS)" (Langacker 1997, 59) ${ }^{6}$, situational background knowledge is salient (ibid, 58).

As a result of the thematic focus of this paper and although CDS is absolutely salient for the functionally correct translational act (Vermeer 1986), the emphasis of our investigation will be on the cultural aspect of CDS.

In summary, our CG tool for the analysis of a PU in the context of translation didactics is based on the implementation of the following classes (functional class 1 , functional class 2): 1. Domains (conceptualization), and 2. focusing as backgrounding vs. foregrounding (construal). Methodologically, in the analysis to be realized in the following section, both classes will be intertwined. The analysis will be depicted by figures that follow the conventional usage of CG.

\subsection{Implementing CG with a Greek PU}

The propositional referential PU on which CG will be implemented is "Ká $\lambda \lambda_{\text {ıo }}$

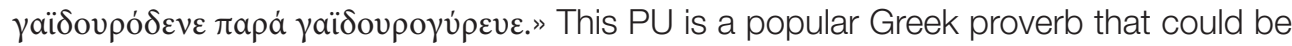
functionally translated into English as «better safe than sorry» or "a stitch in time saves nine». A literal translation, however, of the PU would be «Better to bind the donkey tight than having to seek it out.» As it is the case with all propositional referential PUs, it refers to a subject of conception in a certain situation by using a lexical combination that, as such, does not provide meaning but all together has a metaphorical sense (cf. 2.1). This metaphorical conceptualization constitutes its opacity, its lack of meaning transparency, and, at the same time, the translational difficulty.

\subsubsection{Functional class 1: conceptualization and figurativeness}

According to CG, metaphor resides in a set of connections among a source domain in the matrix, a target space in the matrix, and a blended domain, while the

6. "The CDS is a mental space comprising everything presumed to be shared by the speaker and hearer as the basis for discourse at a given moment.» (Langacker 1997, 59)

Olaf Immanuel SEEL Phraseology and the Implementation of Cognitive Grammar in Translation Didactics
CLINA

vol. 6-2, December 2020, 15-32 elSSN: 2444-1961

Ediciones Universidad de Salamanca - CC BY-NC-ND 
target domain is the one that is structured metaphorically (cf. Langacker 1997, 51). ${ }^{7}$ With regard to the Greek PU under discussion, it is the experience-based truth that it is wise to take precautions if one wants to safeguard one's cherished things or values. The source domain serves as the more literal basis for the metaphorical notion. In the case of the PU under discussion, this base is made up of two domains of the same matrix. Both domains conceptualize the donkey as an animal that has to be bound/ tied up to something if one does not want to lose it. Otherwise, as identified as the conception in the second source domain of the matrix, the donkey will get loose, with the consequence that one will have to be looking for it. The blended domain results from the projection of the source domains on the target domain. By nature, the blended domain is hybrid and fictive and consists of a combination of specific features of the source domains and the target domains.

As we see below, the domains and connections are depicted in the figure 1. The elements of the source domains are a donkey (D), the viewer $(\mathrm{V})$ and the situation of tightly binding the donkey (B) in source domain 1 and the situation of losing the donkey and searching for it (SE) in source domain 2. The viewer can see the donkey in a state of bondage (indicated by a dashed arrow) and the same viewer can also see the donkey having gotten loose (indicated by a dashed arrow), vanishes, with the consequence of having to seek it. Both these source domains are viewed more or less simultaneously (long dashed arrow combining both source domains). The elements of the target domain are a valuableness $(\mathrm{V})$, measures $(\mathrm{M})$ to be taken and the necessary cautiousness $(\mathrm{C})$, the alternatives of losing $(\mathrm{L})$ the valuableness or keeping $(\mathrm{K})$ it, and the «person's 'subject' (S) - that is, the subjective center of consciousness» (Langacker 1997, 52, with reference to Lakoff 1996). The dashed arrow in the target domain represents the experience of either losing or keeping something valuable based on the measures taken and the cautiousness shown. All the dotted lines between the source domains and the target domain manifest their conceptual connections. They show the relationship between those spaces, between the viewer and the subject of consciousness and constitute the basis for the metaphorical construal. Binding the donkey is likened to having safeguarded the valuableness, and searching for the donkey is likened to the thought that one loses its valuableness.

The blended domain is structured by the source domains and their relationship with the target domain. It retains specific elements from both, by merging these elements into a new hybrid conceptual entity which, though fictive, is conceptually and linguistically important (cf. Langacker 1997, 52). The entity labelled V' blends the abstract notion of 'valuableness' with the physical attributes of the animal, the donkey. M'/C' stand for 'measures' and 'cautiousness' but, however, it is conceived as an open scale of possible actions that will either lead to the one or to the other direction (binding and safeguarding or seeking and losing valuableness). S' is still the 'center of

7. Langacker (ibid.) uses the terminology of blending theory (Fauconnier 1997). In accordance with Langacker (ibid, 52), we have adapted it to CG.

Olaf Immanuel SEEL

Phraseology and the Implementation of Cognitive Grammar in Translation Didactics
CLINA

vol. 6-2, December 2020, 15-32

elSSN: 2444-1961

Ediciones Universidad de Salamanca - CC BY-NC-ND 
consciousness' but here it combines the abilities of a viewer who is able to look into M'/C' and scrutinize its content. As it is always the case with metaphors, the blended space represents its essential content, "despite its fictive character, the event that takes place there is precisely what the sentence directly describes» (ibid.).

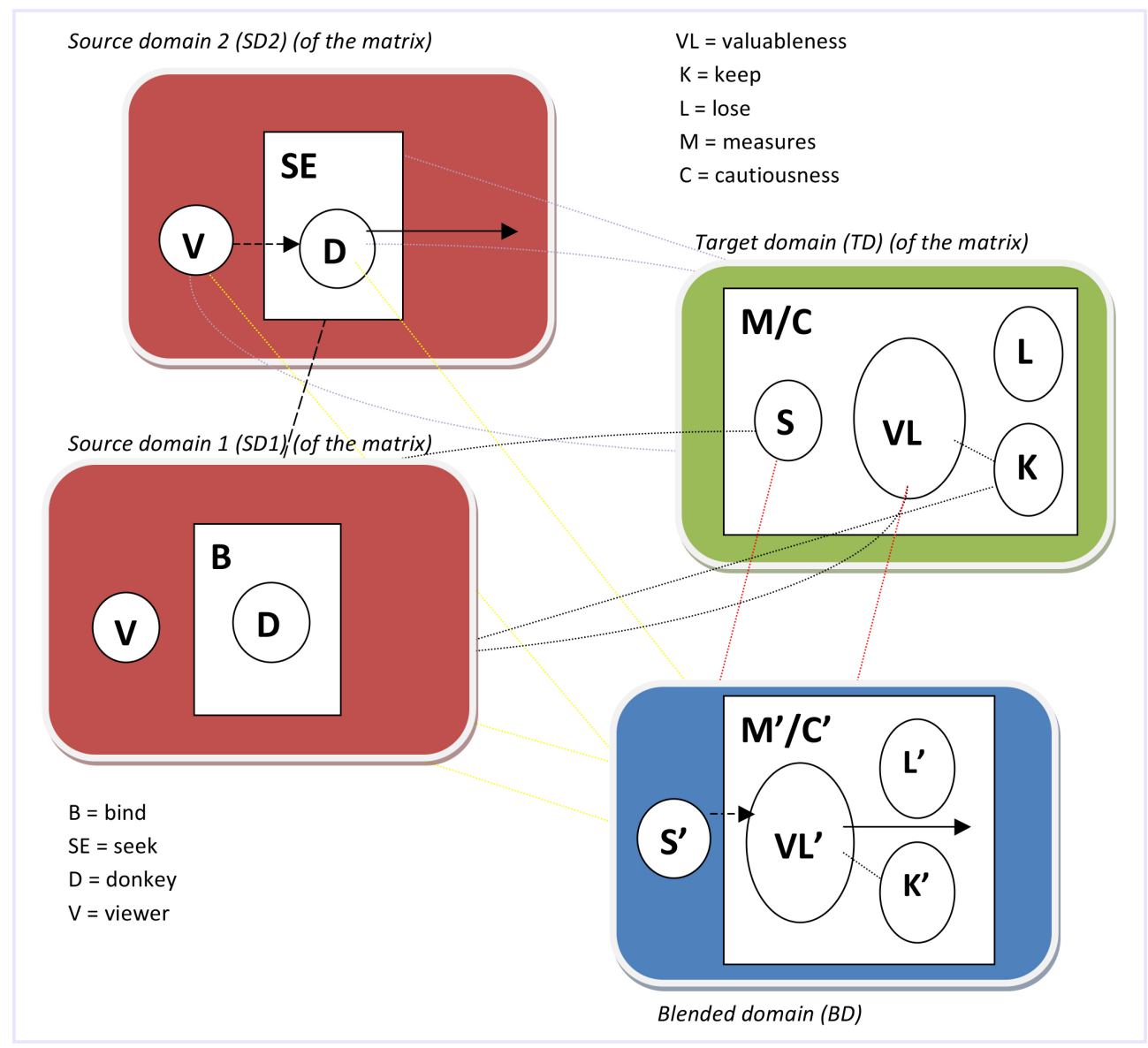

Figure 1: Domain's conceptualization of the Greek PU

In the following section, the functional class 2 of construal will be implemented in order to reveal the culture-boundedness of the Greek PU.

Olaf Immanuel SEEL Phraseology and the Implementation of Cognitive Grammar in Translation Didactics 


\subsubsection{Functional class 2: construal and culture-boundedness}

According to CG, every conceptual manifestation as perception is realized on the juxtaposition of a 'ground' and a 'figure'. This usually involves a departure point and an arrival point, the baseline on which a previous experience can be exploited. CG refers to it as 'background' and 'foreground', as part of the construal class of 'focusing' (cf. 3.1.). Thus, "[w]e can reasonably speak of background and foreground for any case where one conception precedes and, in some way, facilitates the emergence of another [and in] this broad sense, we can say that expressions invoke background knowledge as the basis for their understanding" (cf. Langacker 1997, 58). It is obvious that this background knowledge is equivalent to CDS, part of which is the culturally marked aspect of 'mindset' (Scherner 1984, 62; cf. 3.1.). In metaphors, the source domain(s) is/are precedent of the target domain. This goes for propositional referential PUs too. Let us illustrate in short on the basis of the CG class of focusing, how the culture-boundedness of the Greek PU can be unveiled.

In the Greek PU, the source domains whose central conception-in-matrix is the donkey (D), is concretely anchored in Greek history, traditions with regard to a (former) rural way of life which, however, as well as the knowledge of the (disobedient) nature of the specific animal, are conceptually still parts of the cultural horizon of modern Greeks. Furthermore, the source domains are also anchored in concrete bodily experiences connected to this conceptual horizon, i.e., the ones of binding (B) a donkey and seeking (SE) for it if the former action is not taken care of. Thus, the source domains provide a conceptual background on the grounds of which the target domain is foregrounded and, consequently, can be viewed and, regarding native speakers, to be understood. ${ }^{8}$

In the following figure 2, this relationship between the backgrounded source domains and the foregrounded target domains is illustrated.

8. The blended conception equally merges the joint backgrounding of the source domains and the target domain. However, as the blended conception is not directly connected to the issue of the unveiling of the culture-boundedness of the Greek PU, it does not contribute to the development of cultural competence and, therefore, there will be no further discussion of this particular issue in this paper.

Olaf Immanuel SEEL Phraseology and the Implementation of Cognitive Grammar in Translation Didactics
CLINA

vol. 6-2, December 2020, 15-32 elSSN: 2444-1961

Ediciones Universidad de Salamanca - CC BY-NC-ND 


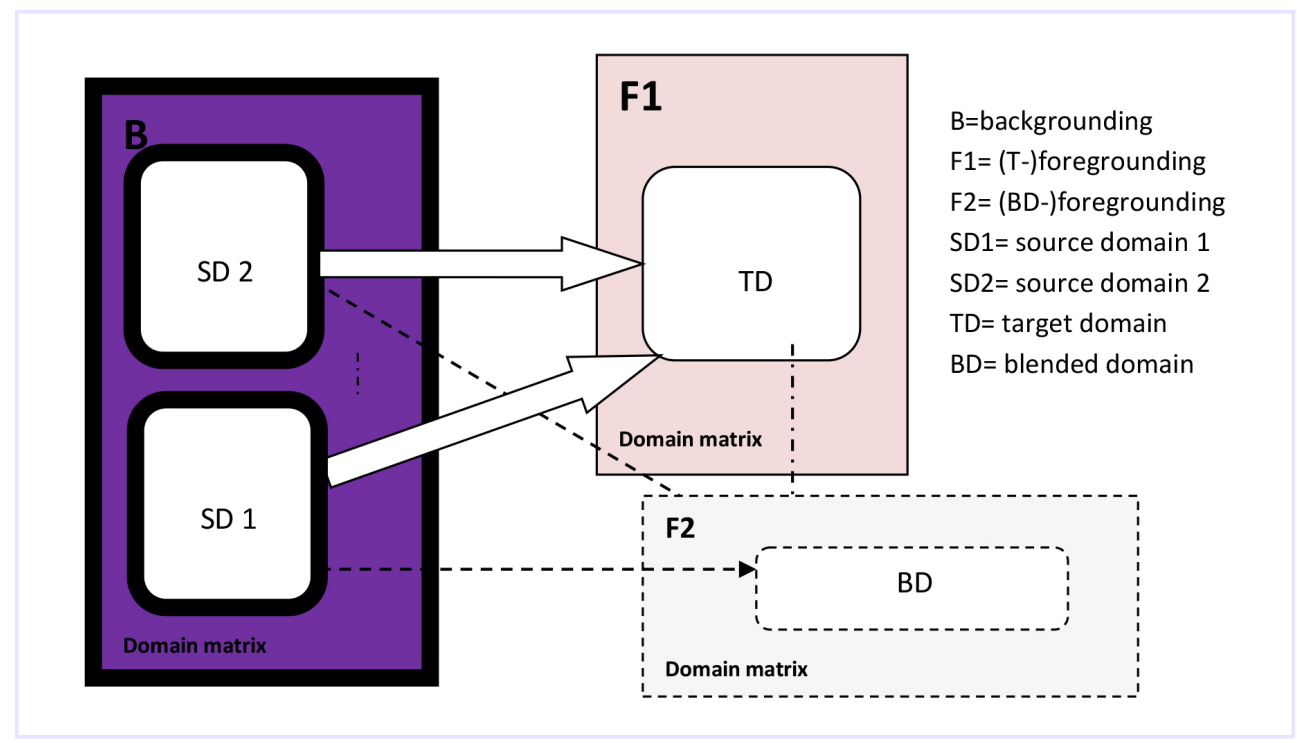

Figure 2: Backgrounding and foregrounding of the Greek PU

While native speakers of Greek unconsciously connect the PU backgrounding and foregrounding and the cultural load involved with their mental experience, for nonnative speakers, however, as it is usually the case with translation trainees and their L2 or L3 working languages, the foregrounded target domain cannot be immediately understood. An adequate understanding presupposes the understanding of the conceptual gamut of the backgrounded source domains, i.e., the culture-specific background knowledge. This, they can acquire with the help of the translation teacher, as well as by reading, research, and continuous contact with the specific working culture. However, in order to do so, they have to first realize that the PU consists of a backgrounded source conceptualization that is intensely culture-bound on which the foregrounded target conceptualization and the overall meaning of the PU is based on. And this is where CG functional class 2 contributes to translation didactics, as by its implementation it assists translation trainees in visually apprehending but also mentally realizing the culture-embeddedness of the PU. Additionally, it offers them and the translation teacher the didactical tools to accurately specify a domain of culturally marked conception, which, they would otherwise not be able to do.

In view of the above, we can also deduce that the figurativeness of the PU, as shown above by CG functional class 1 (cf. figure 1), is genuinely culture-bound as is proven by the implementation of functional class 2 .

Finally, from a methodological point of view, for the implementation of CG in translation didactics it is more appropriate to start with implementing the functional class 1 and then to proceed to the implementation of functional class 2 . This is because,

Olaf Immanuel SEEL Phraseology and the Implementation of Cognitive Grammar in Translation Didactics 
though both classes are conceptually intertwined, functional class 1 establishes the conceptual relationship of the involved domains beforehand, thus creating the basis for the CG class of focusing.

\section{FINDINGS}

On the basis of the above, the implementation of CG serves translation didactics in various ways.

First of all, it offers the methodological conceptual apparatus for the comprehension of the PU. Instead of focusing on the words, the translation trainees become aware of the specific conceptual parts of the PU and their inner conceptual relationships to each other. This unveils the figurative content of the metaphor and their particular constituents, as well as its underlying cultural-embeddedness. The translation trainee thus understands the whole of its conceptual gamut and the conceptual technique of the PU. Altogether, this makes the PU 'visible' and its inherent and culturally marked covered meaning comprehensible. Thus, by the implementation of CG, the translational obstacle of the opacity of the Greek PU is 'removed' and the translation trainees can, in a next step, translate the PU functionally and according to its situational embeddedness. (Cf. Reiß and Vermeer ${ }^{21991 ;}$; Vermeer 1986; Nord 1993).

Moreover, the implementation of the selective CG construal in translation didactics enriches the translation trainee's competence-in-culture (cf. footnote 4) through an indepth-analysis of the culturally marked backgrounding of the source-PU (cf. figure 2). Through this, the mindset of the source-culture will be strengthened. At the same time, this is also associated with the amelioration of the translation trainee's competencebetween-cultures (cf. ibid.). Given the central axiom of functional translation theory that cultures conceptualize and verbalize the world in different ways and with different means (cf. Reiß and Vermeer ${ }^{21991), ~ a ~ f u n c t i o n a l l y ~ c o r r e c t ~ t r a n s l a t i o n ~ o f ~ a ~ s o u r c e-~}$ PU implies that translation trainees will have to endeavour to find a situationally and functionally appropriate target-rendering of the source-PU which may very possibly be a suitable target-PU. In accordance with Langacker $(1997,43)$ that "construal refers to our manifest ability to conceive and portray the same situation in alternate ways", by also implementing CG functional classes in the translation classroom, the chosen target-PU, translation trainees will thus improve their ability of comparing the two working cultures and will be able to work out the differences of conceptualization and verbalization in both their working cultures. This will definitely improve their overall translation competence.

Last but not least, another asset of the instrumentalization of CG in translation didactics is the fact that translation trainees acquire a metalanguage on the analysis of PUs and other culture-bound concepts. Besides the fact that CG metalanguage will provide with a conceptual method of approaching language manifestations of these kinds, the use of CG metalanguage will enhance and accelerate in-class-

Olaf Immanuel SEEL Phraseology and the Implementation of Cognitive Grammar in Translation Didactics
CLINA

vol. 6-2, December 2020, 15-32

eISSN: 2444-1961

Ediciones Universidad de Salamanca - CC BY-NC-ND 
communication and may be of particular benefit for translation trainees with spatial and visual learning habits and styles.

\section{CONCLUSION}

As I have shown, CG can be of multiple uses for translation didactics. Most of all, if properly implemented, it contributes to the amelioration of the translation trainee's competence-in-culture and of their competence-between-cultures. This results in an improvement of their overall translation competence. Furthermore, the instrumentalization of CG for translation didactics has also shown to be easily teachable by the translation teacher. Though this presupposes that the translation teacher invests some time in order to get acquainted with the principles of $\mathrm{CG}$, the results and the number of its assets make it worth the effort.

Finally, given the refined theoretical apparatus of CG and its proven practical applicability on the analysis of language (Langacker 1987; 1991; 1997), it seems reasonable to suggest that CG can very possibly constitute an effective conceptual tool to assist translation didactics not only for the in-depth-analysis of PUs and of their culture-boundedness but also for other linguistic manifestations that pose translational challenges.

\section{REFERENCES}

ARroyo, Maríza Diaz. 2009. «Phraseological Units: Persuasion and Translation», Revista Alicantina de Estudios Ingleses (22): 45-62.

BAKER, Mona. 1992. In Other Words. A Coursebook on Translation. London: Routledge

Burger, Harald. [1998]. ${ }^{42010 . ~ P h r a s e o l o g i e . ~ E i n e ~ E i n f u ̈ h r u n g ~ a m ~ B e i s p i e l ~ d e s ~ D e u t s c h e n . ~ B e r l i n: ~}$ Erich Schmidt Verlag.

Burger, Harald, Annelies Buhofer and Ambros Siam. 1982. Handbuch der Phraseologie. Berlin/ New York: Walter de Gruyter.

CORPAS PASTOR, Gloria. 1996. «La fraseología en los diccionarios bilingües». In Estudios de historia de la lexicografía del español, ed. by Manuel Alvar Ezquerra. Málaga: Servicio de Publicaciones de la Universidad de Málaga, 167-182.

CORPAS PASTOR, Gloria. 2001. «La traducción de las unidades fraseológicas: técnicas y estrategias». In La lingüística aplicada a finales del siglo XX. Ensayos y propuestas, ed. by Isabel de la Cruz, Carmen Santamaría, Cristina Tejedor and Carmen Valero. Alcalá: Universidad de Alcalá, 779-787.

Fauconnier, Gilles. 1997. Mappings in Thought and Language. Cambridge: Cambridge University Press.

GAWEL, Anieszka. 2014. «Ein Ereignis - viele Interpretationen Zur Konstruktion der Szene in Presseartikeln und Web-Einträgen». Zeitschrift des Verbandes polnischer Germanisten (3) 2: 131-150.

Olaf Immanuel SEEL Phraseology and the Implementation of Cognitive Grammar in Translation Didactics
CLINA

vol. 6-2, December 2020, 15-32

elSSN: 2444-1961

Ediciones Universidad de Salamanca - CC BY-NC-ND 
GLÄSER, Rosemarie. 1984. "The translation aspect of phraseological units in English and German». Papers and Studies in Contrastive Linguistics (18): 123-134.

HallsteinsdótTIR, Erla. 1997. «Aspekte der Übersetzung von Phraselogismen am Beispiel Isländisch - Deutsch». In Translationsdidaktik. Grundfragen der Übersetzungswissenschaft, ed. by Eberhard Fleischmann, Wladimir Kutz and Peter A. Schmitt. Tübingen: Narr Verlag, 561569.

HallsteinsdótTIR, Erla. 2011. «Phraseological Competence and the Translation of Phrasemes». In Multi-Lingual Phraseography: Second Language Learning and Translation Applications, ed. by Antonio Pamies, Lucía Luque, Nadal and José Manuel Pazos Bretaña. Baltmannsweiler: Schneider Verlag Hohengehren, 279-288.

Hallsteinsdóttir, Erla and Ken Joensen Farø. 2010. «Interlinguale Phraseologie: Theorie, Praxis und Perspektiven». In Yearbook of Phraseology, 125-159.

KITTEL, Harald, Armin Paul Frank, Norbert Greiner, Theo Hermans, Werner Koller, José Lambert, and Fritz Paul. eds. 2004. Übersetzung-Translation-Traduction (Teillband I). Berlin/New York: Walter de Gruyter.

Kuzmin, Sergey. 2007. Idiomatic Translation from Russian into English (Theory and Practice). Moscow: Flinta, Nauka.

LACKOFF, George. 1996. «Sorry, I'm Not Myself Today: The Metaphor System for Conceptualizing the Self». In Spaces, Worlds, and Grammar, ed. By Gilles Fauconnier and Eve Sweetser. Chicago: University of Chicago Press, 91-123.

LANGACKER, Ronald. 1987. Foundations of Cognitive Grammar, Vol. 1, Theoretical Prerequisites. Stanford U. P.: Stanford.

LANGACKER, Ronald W. 1991. Foundations of Cognitive Grammar, Vol. 2, Descriptive Application. Stanford U. P.: Stanford.

LANGACKER, Ronald W. 1997. "The contextual basis of cognitive semantics». In Language and Conceptualization, eds. Jan Nuyts and Eric Pederson. Cambridge: Cambridge University Press, 229-252.

LANGACKER, Ronald W. 2008. Cognitive Grammar. A Basic Introduction. Oxford: Oxford University Press.

Mogorrón Huerta, Pedro and Antonio Albaladejo-Martínez. eds. 2018. Fraseología, Diatopía y Traducción / Phraseology, Diatopic Variation and Translation. Amsterdam/Philadelphia: Benjamins.

NIDA, Eugene and Charles TABER. 1969. The Theory and Practice of Translation. Leiden: Brill.

Nord, Christiane. 1993. Einführung in das funktionale Übersetzen: am Beispiel von Titeln und Überschriften. Tübingen/Basel: Francke.

ReI $\beta$, Katharina and Hans J. VermeER. [1984], ${ }^{21991 . ~ G r u n d l e g u n g ~ e i n e r ~ a l l g e m e i n e n ~ T r a n s l a t i o n s-~}$ theorie. Tübingen: Niemeyer.

RoBerTs, Roda. 1998. «Phraseology and translation». In La traducción: orientaciones lingüísticas y culturales, eds. Fernández Nistal, Purificación and José María Bravo Gozalo. Valladolid: Servicio de Publicaciones de la Universidad, 61-77.

Sabban, Anette. Ed. 1999. Phraseologie und Übersetzen. Bielefeld: Aisthesis-Verlag.

SCHERNER, Maximilian. 1984. Sprechen im situativen Kontext. Theorie und Analyse spontanen Sprachgebrauchs. Tübingen: Niemeyer Verlag.

SeEL, Olaf I. 2015. "The Pragmatic-Functional Nature of Intralingual Translation and its Affinity to Top-Down-Procedures». Parallèles 27 (2): 71-82. (https://www.paralleles.unige.ch/files/6815/2839/0411/Paralleles_27-2_2015_seel.pdf)

Olaf Immanuel SEEL Phraseology and the Implementation of Cognitive Grammar in Translation Didactics
CLINA

vol. 6-2, December 2020, 15-32

elSSN: 2444-1961

Ediciones Universidad de Salamanca - CC BY-NC-ND 
SeEL, Olaf I. 2015a. «Intercultural Pragmatics and Text Typology: An Integrated Approach to Translation Teaching». In Handbook of Research on Teaching Methods in Language Translation and Interpretation", ed. By Ying Cui and Wei Zhao. Pennsylvania: IGI-Global, 199-219.

SubBotina, Victoria. 2013. «Challenges of Translating Phraseological Units». Procedia - Social and Behavioral Sciences (70): 1487-1492.

SulkowSKA, Monika. 2013. «Figement en didactique de traduction». Neophilologica (25): 195207.

VERMEER, Hans J. 1986. «Übersetzen als kultureller Transfer». In Übersetzungswissenschaft. Eine Neuorientierung, ed. Snell-Hornby, Mary. Tübingen: Francke, 30 - 53.

WILDGEN, Wolfgang. 2014. "Kognitive Grammatik. Textbeitrag zum Handbuch WSK Cognitive Grammar». Conference paper. Accessible under: https://www.researchgate.net/publication/270886582_Kognitive_Grammatik_Textbeitrag_zum_Handbuch_WSK_Cognitive_ Grammar.

WiTtE, Heidrun. 1987. "Die Kulturkompetenz des Translators - Theoretisch-abstrakter Begriff oder realisierbares Konzept?». TextconText (2): 109-136.

WITTE, Heidrun. 2000. Die Kulturkompetenz des Translators: begriffliche Grundlegung und Didaktisierung. Tübingen: Stauffenburg.

ZIEM, Alexander. (n.d.). «Kognitive Linguistik heute: ein Überblick über zentrale Positionen und Konzepte». Accessible under: https://www. phil-fak.uni-duesseldorf.de/fileadmin/Redaktion/ Institute/Germanistik/Abteilungl/Mitarbeiter/ziem/Ziem_KognitiveLinguistikHeute.pdf

Olaf Immanuel SEEL Phraseology and the Implementation of Cognitive Grammar in Translation Didactics 